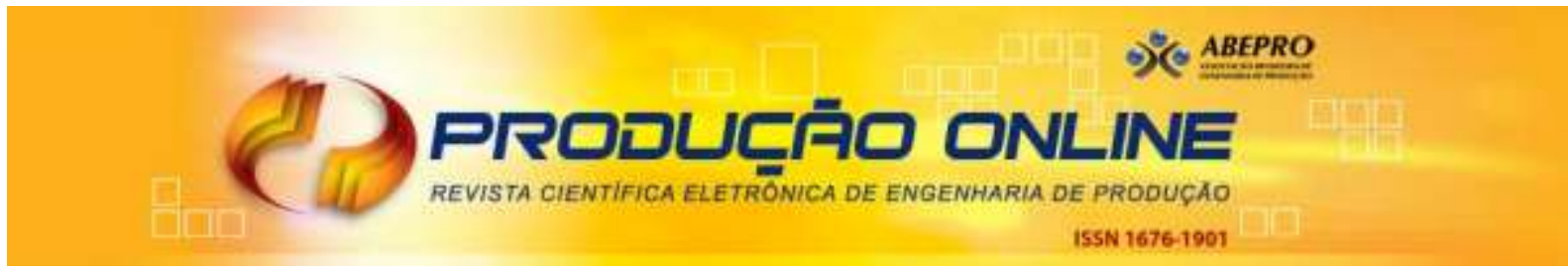

\title{
UM ESTUDO DE CASO SOBRE A TRANSFORMAÇÃO DE UMA TRANSPORTADORA TRADICIONAL EM UM OPERADOR LOGÍSTICO
}

\section{A CASE STUDY ABOUT THE TRANSFORMATION OF A TRADITIONAL CARRIER IN A LOGISTIC PROVIDER}

\author{
Gabriel Sperandio Milan* E-mail: gsmilan@ucs.br \\ Tânia Craco*E-mail: tcraco@yahoo.com.br \\ Deonir De Toni* E-mail: deonirdt@terra.com.br \\ Carlos Alberto Costa*E-mail: cacosta@ucs.br \\ *Universidade de Caxias do Sul (UCS), Caxias do Sul, RS
}

\begin{abstract}
Resumo: A terceirização das atividades logísticas se tornou uma prática comum dentro das estratégias das empresas. Desta forma, o uso da prestação de serviços especializados por meio de operadores logísticos vem surgindo como uma forma para aumentar a competitividade das empresas. Visando atender a um mercado em expansão e agregar valor ao seu negócio, muitas transportadoras tem se transformado em operadores logísticos. Sendo assim, este artigo apresenta uma análise sobre a organização, adaptação e evolução da transformação de uma transportadora de cargas tradicional em um operador logístico. A metodologia de pesquisa utilizada foi qualitativo-exploratória, implementada por meio de um estudo de caso único. Para a coleta de dados, foram realizadas entrevistas individuais em profundidade, com uma abordagem semi-estruturada. Além disso, foram utilizados dados provenientes da observação direta e de pesquisa documental. Para a elaboração dos resultados foi aplicada a técnica de análise de conteúdo. A empresa, ao agregar serviços, procurando relacionamentos de longo prazo com seus clientes, aumentou sua competitividade. Tal mudança oportunizou vantagens como a otimização dos recursos disponíveis e a melhoria na qualidade dos serviços prestados. A transformação da empresa em um operador logístico repercutiu em maior credibilidade e ampliação do seu mix de serviços, resultando no aumento de seu faturamento e lucratividade e em um diferencial perante a concorrência.
\end{abstract}

Palavras-chave: Logística. Operador Logístico. Estratégia. Serviço ao Cliente. Competitividade.

Abstract: Logistics operation outsourcing has become a regular practice for many companies strategy. As result, the use of specialized services provided by logistic operators appears as a way to increase company's competitiveness. In order to respond to this need and add value to services offered, many cargo transport companies have changed their business to logistic operators. Thus, this article presents an analysis related to the organization, adaptation and evolution of a traditional cargo transport company to become a logistic operator. A qualitative-exploratory methodology, implemented by means a single case study, was used to develop this research. To data collection, in depth individual interviews were done, with a semi-structured approached. In addition, data were used from direct observation and documental research. The techniques used to analyze the results are understood by content analysis. As result of the transformation process, the organization increased its competitiveness, by value aggregation to its services and looking for long term relationship with its customers. Also, optimization of available and existing resources and quality improvement of provided services were perceived by company during the transformation process. The company transformation into a logistic operator reflected in greater credibility and expansion of the services offered, resulting in billing and profitability increase and a differential against the competitors.

Keywords: Logistics. Logistic Operator. Strategy. Customer Service. Competitiveness. 


\section{INTRODUÇÃO}

Com o acirramento na competição, globalização do mercado e avanços tecnológicos, as empresas estão sendo forçadas a adotar melhores práticas mercadológicas para garantir a sua sobrevivência e perpetuação, agregando valor aos seus clientes e acionistas (SEMEIJN, 1995; LANGLEY et al., 2005), buscando maior eficiência não apenas internamente, mas em todos os elos de suas cadeias produtivas (SOUZA; KLIEMANN NETO; ANZANELLO, 2012). Em um mercado dinâmico, a velocidade de resposta é um fator determinante para a construção de possíveis vantagens competitivas. Neste sentido, Barad e Sapir (2003) salientam que o objetivo central da logística é a resposta rápida, em um ambiente altamente competitivo, e que apresenta como característica constantes mudanças e a incidência de incertezas.

Stock, Greis e Kasarda (1998) ressaltam a velocidade (encurtamento do tempo de execução de atividades) e a confiabilidade como aspectos importantes para a logística, pois as empresas estão buscando dinamizar seu fluxo de bens e de serviços (MANUJ; MENTZER, 2008; WAGNER; BODE, 2008), agregando valor às suas ofertas (JOHNSON; PYKE, 2000), procurando minimizar os custos de todo o sistema, desde que satisfaçam os clientes e os requisitos de qualidade (SIMCHILEVI; SNYDER; WATSON, 2002; BOWERSOX; CLOSS; STANK, 2003). Daí a importância das empresas acompanharem os resultados provenientes dos seus indicadores de desempenho logístico em suas operações (MENEZES; GUIMARÃES; SELLITTO, 2008).

A logística pode ser compreendida como um serviço que afeta os custos e o lucro das empresas e a satisfação dos clientes (STOCK; LAMBERT, 2001; McGINNIS; KOHN, 2002). E a terceirização deste serviço, que era baseada na redução de custos e liberação de capital, vem apresentando um papel estratégico, focada na melhoria do nível de serviço aos clientes e maior flexibilidade em relação às suas exigências (SKJOETT-LARSEN, 2000; CHEONG, 2004; AKTAS; ULENGIN, 2005). Como as empresas geralmente buscam soluções externas, concentrando-se em suas core competences (HAMEL; PRAHALAD, 2000; SINK; LANGLEY, 1997), isto coloca os operadores logísticos como bons parceiros de negócio 
(CHRISTOPHER; TOWILL, 2001), podendo contribuir para a redução dos riscos logísticos atinentes à transferência de know how e de tecnologia (PICININ; KOVALESKI; REIS, 2010) e para a melhoria da satisfação dos clientes e do desempenho das empresas (BASK, 2001).

Bhatnagar e Viswanathan (2000) e Wong et al. (2000) defendem que os operadores logísticos podem colaborar com as empresas gerando outros benefícios operacionais, tais como: redução dos níveis de estoque, tempos de ciclos dos pedidos, prazos de entrega e melhoria no atendimento aos clientes. Por isso, os operadores logísticos desempenham um papel relevante na economia mundial (BOT; NEUMANN, 2003).

A indústria mundial de transportes vem absorvendo transformações que se desenvolvem no ambiente competitivo. Estas transformações favorecem o surgimento de novas e crescentes demandas dos embarcadores, que são percebidas na forma de aumento da competição, necessidade de integração com prestadores de serviços de outras modalidades para a movimentação de cargas, pressão por preços mais competitivos, redução de custos e melhorias na qualidade dos serviços (NEUSCHEL; RUSSELL, 1998; LAISI; HILMOLA; SUTELA, 2012).

A partir desta oportunidade de mercado começaram a surgir empresas que, ao invés de ofertarem apenas o serviço de transporte, passaram a oferecer soluções que integram outras atividades ao serviço desejado, emergindo os serviços logísticos relacionados a processos e atividades interligados por tecnologias, tais como EDI - Electronic Data Interchange, e compreendidos por serviços terceirizados, como a consolidação de cargas, armazenagem e gerenciamento de suprimentos e fornecedores (MURPHY; POIST, 2000). Como o operador logístico presta serviços especializados (LARGE, 2007), apresentando competência reconhecida em atividades logísticas, desempenha funções que podem englobar todo o processo logístico de uma empresa-cliente ou somente parte dele. Os especialistas em logística dizem que é possível reduzir de $15 \%$ a $20 \%$ somente em custos com armazenagem e transporte (BOT; NEUMANN, 2003). A área de transportes ou de movimentação de cargas passou de um mero integrante operacional para um elemento capaz de gerar uma possível fonte de vantagem 
competitiva e níveis de serviços aos clientes mais qualificados (STANK; GOLDSBY, 2000; ALFREDSSON; HERTZ, 2003; BOWERSOX; CLOSS; STANK, 2003).

No Brasil, com a crescente importância da logística e a procura por melhores níveis de serviço aos clientes (MILAN, 2006; VIEIRA; MILAN; OTT, 2008), os gestores vêm terceirizando seus serviços logísticos. As transportadoras estão se deparando com esta oportunidade de mercado, buscando uma evolução em seus serviços. A qualidade apresentada pelos serviços prestados pelos operadores logísticos pode propiciar alternativas de diferenciação na forma com que os clientes percebem o serviço em relação à concorrência (SO et al., 2006).

As empresas precisam, então, se organizar melhor, tornando-se mais ágeis e flexíveis que seus competidores, alinhadas com o mercado em que atuam e dando maior ênfase a possíveis diferenciais competitivos advindos da gestão do processo e das atividades logísticas (FLINT; LARSSON; GAMMELGAARD, 2005). Para tanto, surge o operador logístico, que deverá ser um parceiro de negócios eficiente e eficaz para poder unir os elos da cadeia de suprimentos, agregando valor aos clientes. Para isso, é essencial escolher um operador logístico que esteja comprometido com a organização no desenvolvimento de soluções (TIBBEN-LEMBKE; ROGERS, 2006; JESPERSEN; SKJOETT-LARSEN, 2005).

Neste horizonte, por meio de um estudo de caso único, o presente trabalho pretendeu analisar o processo de transformação de uma transportadora tradicional em um operador logístico no sentido de agregar valor aos serviços prestados aos clientes e ampliar o seu nível de competitividade.

\section{REVISÃO BIBLIOGRÁFICA}

\subsection{O Operador Logístico e Diferenças com as Transportadoras Tradicionais}

A logística começou a ganhar importância com a quebra do paradigma da produção em massa, ainda mais com a filosofia just in time e da produção enxuta, pois as empresas passaram a demandar entregas de matérias-primas e produtos em prazos e lotes menores, tornando a logística uma atividade complexa, requerendo especialistas para gerenciá-la (RAO; SWARUP, 2001). Em acréscimo, Fuchs (2003) 
comenta que o relacionamento com os clientes e a rapidez em disponibilizar informações são considerados fatores críticos de sucesso, enquanto que a interação com os clientes, a capacidade / velocidade de fabricação, entrega do produto e informações correlatas são vistos como direcionadores de valor. Emerge, então, a necessidade da prestação de serviços logísticos, configurando-se a oportunidade da presença do operador logístico, que pode suprir demandas por serviços logísticos de forma integrada, customizada e personalizada.

Como a tendência das empresas é a de terceirizar boa parte dos serviços logísticos, mediante a parceria com operadores logísticos, a sua importância na competitividade das empresas vem aumentando (DORNIER et al., 1998). Nos Estados Unidos, com base em uma pesquisa realizada em 2004, foi evidenciado que pelo menos $80 \%$ das grandes empresas manufatureiras utilizavam os serviços de PSLs (prestadores de serviços logísticos) (BENTZ; LIEB, 2005). A mesma pesquisa, implementada em 1991, mostrou que apenas 38\% das empresas terceirizavam atividades logísticas. Para Lieb e Miller (2002), a globalização dos mercados favoreceu a expansão dos operadores logísticos em maior escala.

Devido à velocidade com que novos produtos e mercados são desenvolvidos, fica difícil as empresas preverem suas necessidades logísticas. Já os operadores logísticos, por atuarem com diversos clientes e em diferentes mercados, e por necessitarem atualizar-se constantemente, desenvolvendo sua infraestrutura, recursos humanos e tecnologias pertinentes, apresentam maior conhecimento e flexibilidade para oferecer soluções logísticas customizadas ( $\mathrm{LYNCH}, 2000)$.

Para Coyle, Bardi e Langley (2003), o operador logístico é um fornecedor externo, um provedor de serviços que executa a totalidade ou parte das funções logísticas de uma empresa e que abrange serviços como transporte, armazenagem e distribuição. Podem suprir serviços de gestão e operação de transportes, movimentação e armazenagem de materiais e relativas aos estoques. Porém, há outras atividades que estão sendo agregadas no sentido de diferenciar um operador logístico dos demais, tais como montagem de kits ou de componentes, atividades de importação e/ou exportação e coleta programada de suprimentos (milk run).

Esta terminologia, operador logístico surgiu nos Estados Unidos na década de 80 e, atualmente, é fortemente difundida nos países europeus com a denominação 
Third-Party Logistics Provider (3PL) (LIEB; RANDALL, 1996). No Brasil, decorre do conceito de terceirização de serviços logísticos (outsourcing) ou contrato logístico. Berglund, Sharman e Wandel (1999) associam a expressão 3PL à empresa que oferece, por meio de um contrato, os serviços de operações e gerenciamento de transporte, movimentação e armazenagem.

Um operador logístico engloba todo o tipo de atividades logísticas, por mais simples que sejam, não refletindo necessariamente os avanços tecnológicos e operacionais inerentes a uma Supply Chain (Van LAARHOVEN; BERGLUNG; PETER, 2000). É uma empresa que conduz o planejamento, implantação e controle, de maneira eficiente, do fluxo de material através da cadeia de suprimentos, e todos os serviços e informações associadas, do ponto de origem até o ponto de consumo, satisfazendo exigências dos clientes (SINK; LANGLEY; GIBSON, 1996; RAZZAQUE; SHENG, 1998; COYLE; BARDI; LANGLEY, 2003; TUCEN; ALPAN, 2010).

Há que se ressaltar que todo operador logístico pode ser considerado um PSL, mas nem todo PSL, como é o caso de uma transportadora tradicional, pode ser considerado um operador logístico (VIRUM, 1993; ALFREDSSON; HERTZ, 2003). $\mathrm{Na}$ Figura 1, mostra-se a comparação entre as principais características de uma transportadora tradicional e um operador logístico (FLEURY, 2004).

Figura 1 - Diferenças entre transportadoras e operadores logísticos

\begin{tabular}{|l|l|}
\hline \multicolumn{1}{|c|}{ Transportadoras (Serviços Tradicionais) } & \multicolumn{1}{|c|}{ Operadores Logísticos } \\
\hline Ofertam serviços genéricos (commodities) & Ofertam serviços customizados (personalizados) \\
\hline $\begin{array}{l}\text { Tendem a se concentrar apenas em uma } \\
\text { atividade logística (ex.: transporte, estoques ou } \\
\text { armazenagem) }\end{array}$ & $\begin{array}{l}\text { Oferecem múltiplas atividades de forma integrada } \\
\text { (ex.: transporte, gestão de estoques e } \\
\text { armazenagem) }\end{array}$ \\
\hline $\begin{array}{l}\text { O objetivo do contratante do serviço é a a } \\
\text { minimização dos custos específicos à atividade } \\
\text { contratada }\end{array}$ & $\begin{array}{l}\text { Objetivo do contratante é reduzir custos logísticos, } \\
\text { melhorar os serviços ao cliente e aumentar a } \\
\text { flexibilidade e agilidade fabril / operacional }\end{array}$ \\
\hline $\begin{array}{l}\text { Contratos de serviços tendem a ser de curto ou } \\
\text { médio prazos (entre } 6 \text { meses e 1 ano) }\end{array}$ & $\begin{array}{l}\text { Contratos de serviços tendem a ser de longo } \\
\text { prazo (entre 5 a 10 anos) }\end{array}$ \\
\hline Know how tende a ser limitado e especializado & $\begin{array}{l}\text { Capacidade elevada de análise e planejamento } \\
\text { logístico e de toda a parte operacional }\end{array}$ \\
\hline $\begin{array}{l}\text { Negociações para os contratos tendem a ser } \\
\text { rápidas e em um nível operacional }\end{array}$ & $\begin{array}{l}\text { Negociações para os contratos tendem a ser } \\
\text { longas e em um alto nível de gestão (tático e/ou } \\
\text { estratégico) }\end{array}$ \\
\hline
\end{tabular}




\subsection{Vantagens e Desvantagens da Utilização de um Operador Logístico}

As vantagens do uso de operadores logísticos estão na possibilidade de apoio consistente na penetração em novos mercados e redução dos riscos de investimentos inerentes à propriedade de ativos logísticos, tais como caminhões, implementos e armazéns (DORNIER et al., 2000). Como é o caso do acesso a novas tecnologias e a soluções inovadoras, o operador logístico pode oferecer vantagens relacionadas à redução de custos, tais como: redução dos investimentos em ativos (transformando custos fixos em variáveis) e dos custos de manutenção de máquinas e equipamentos (BARDI; TRACEY, 1991).

Por atenderem a diversos clientes, com necessidades diferentes, são capazes de melhor utilizar suas capacidades, obtendo economias de escala (VAN DAMME; PLOSS VAN AMSTEL, 1996) e ainda de auxiliar na redução de temas e fontes de conflito existentes nos canais de distribuição ou em cadeias produtivas (MILAN; DORION; MATOS, 2012). Podem ser citados outros benefícios, incluindo a redução nos níveis de estoque, tempos de ciclo dos pedidos, prazos de entrega e melhoria no atendimento aos clientes (DAUGHERTHY; STANK; ROGERS, 1996; BHATNAGAR; VISWANATHAN, 2000; WONG et al., 2000).

As desvantagens podem ser identificadas em quatro principais dimensões: perda ou dificuldade de acesso a informações-chave do mercado: o contato diário com fornecedores e clientes é essencial para manter os gestores da empresa sintonizados com as oportunidades e ameaças de mercado. Ao delegar certas funções, processos ou atividades a um operador logístico, a organização corre o risco de perder a sensibilidade de identificar, no tempo certo, mudanças ou tendências de mercado; falta de percepção por parte do operador logístico acerca dos objetivos mercadológicos do cliente: no dia a dia as organizações são obrigadas a fazerem escolhas entre os diversos objetivos relativos ao negócio (custos, margens de lucro e rentabilidade, flexibilidade e foco em certos mercados e/ou clientes). Estas escolhas devem respeitar uma estratégia definida e modificada à medida que se alteram as condições de exigência do mercado; incapacidade do operador logístico de cumprir com as suas obrigações e metas compromissadas com o cliente: pode ocorrer que o operador logístico, na ânsia de assinar um 
contrato, prometa muita coisa que não possa cumprir, gerando prejuízo de ambos os lados; e dependência que pode ocorrer do cliente em relação ao operador logístico: trocar de operador ou mesmo assumir de volta as operações, então terceirizadas, pode causar transtornos, como deixar ativos na guarda de terceiros, informações e know how, podendo causar um excessivo aumento de custos operacionais para o cliente (DORNIER et al., 1998; STOCK; LAMBERT, 2001).

Embora os operadores logísticos possam aumentar a flexibilidade em relação ao mercado (investimentos) e à procura de bens (flexibilidade de volume), a falta de capacidade de resposta às necessidades dos clientes é citada como um possível problema (VAN DAMME; PLOSS VAN AMSTEL, 1996). Outros problemas seriam a interrupção do serviço, dos fluxos de entrada, qualidade inadequada, perda de feedback do cliente e incapacidade dos operadores logísticos em lidar com necessidades especiais e emergências circunstanciais (SINK; LANGLEY, 1997; VAN LAARHOVEN; BERGLUND; PETER, 2000; SVENSSON, 2001).

Outro aspecto relevante é o nível de dependência da empresa contratante em relação ao operador logístico. A dependência diz respeito à necessidade, em alto grau, de se manter um relacionamento com um determinado parceiro de negócios para que seja possível atingir determinados objetivos e metas ou um nível de performance específico (PALMATIER; DANT; GREWAL, 2007). A dependência será maior quando os serviços obtidos são altamente valorizados e quando os serviços obtidos excedem os serviços ofertados por qualquer outro fornecedor alternativo (HEIDE; JOHN, 1988). Liu e Wang (2009) colocam que a contratação de operadores logísticos está sendo vista como um fator relevante no crescimento das empresas, pois ao contratarem podem se concentrar no seu negócio, melhorando a sua eficiência e a utilização de recursos desta forma aumentando a lucratividade.

\subsection{Os Desafios Inerentes aos Operadores Logísticos}

A competição entre operadores logísticos é intensa e seus principais desafios são manter seus clientes com contratos ativos e os lucros sob fortes pressões de preço, considerando-se os efeitos decorrentes da globalização, a complexidade intrínseca ao relacionamento com os clientes, entregas em novas regiões 
geográficas (dispersão geográfica), tecnologias de ponta e o surgimento dos 4PLs Fourth-party Logistics (VASILIAUSKAS; BARYSIENĖ, 2008; RAO; YOUNG, 1994).

Os desafios dos operadores logísticos podem ser diferenciados pelo grau de "tangibilidade" dos serviços prestados. No nível superior encontra-se a camada de configuração da rede logística (mais tangível) e no final a gestão de relacionamentos (menos tangível) (CHEONG, 2004). Em relação ao gerenciamento dos recursos e informações, Van Hoek e Chong (2001) fazem referência aos 4 PLs como sendo um novo rumo para a terceirização, propiciando a integração de toda a cadeia de suprimentos, onde são reunidos e gerenciados todos os recursos, capacidades e tecnologias, de terceiros ou próprias.

O operador logístico, ao assumir a função logística dos seus clientes, geralmente tem que criar uma rede logística para suportar o fluxo de materiais e produtos da planta fabril do cliente até os consumidores finais, havendo, ou não, a interface com outros intermediários no contexto dos canais de distribuição. Para tanto, os operadores logísticos necessitam de soluções efetivas para ajudar aos seus clientes a projetar e/ou melhorar as suas redes logísticas, operando com custos mínimos e satisfazendo as exigências de seus compradores (clientes e/ou consumidores finais). A maior barreira na interação entre uma empresa-cliente e seu operador logístico está na troca de informações e no processo de comunicação, bem como na construção e manutenção da confiança entre as partes (CHEONG, 2004).

Por isso, a adoção da Tecnologia da Informação (TI) e de uma comunicação eficaz se tornou crítica para os operadores logísticos na integração da cadeia (EVANGELISTA; SWEENEY, 2003; MIN; JOO, 2009). Para Alfredsson e Hertz (2003), o problema enfrentado pelos operadores está em encontrar o equilíbrio em sua capacidade de adaptação às necessidades dos clientes e a organização dos seus processos para o desenvolvimento de suas competências, podendo desenvolver a sua especialização e a sua capacidade de apoiar a expansão nacional e internacional da cadeia na qual está inserido (BOURLAKIS; BOURLAKIS, 2005).

O transporte gera custos logísticos expressivos para as empresas. Tendo em vista certas exigências, como é o caso da entrega rápida com confiabilidade elevada, às vezes não é possível prestar este nível de serviço aos clientes, seja pela 
indisponibilidade de algum ativo (equipamentos especiais) seja pelo manuseio especializado de cargas. Assim, os operadores logísticos surgem como especialistas capazes de responder a situações pontuais, customizadas, em apoio aos seus clientes (SANTOS; SOUZA JUNIOR; BOUZADA, 2012; MOURA; BOTTER, 2011).

Os operadores logísticos, portanto, irão se deparar com obstáculos e oportunidades de mercado em função do crescimento dos serviços, ambientes mais complexos e dinâmicos, pela globalização, acirramento da competitividade, aumento de demanda e escassez de recursos (GRACHT; DRAKOW, 2010) e da necessidade de aplicação de modelos e técnicas de gestão que lhes possibilitem enfrentar tal contexto com maior propriedade, eliminando desperdícios e aumentando sua produtividade e eficiência (FERNANDES; MARINS, 2012; JUNQUEIRA et al., 2007). Inclusive, Gunasekaran e Ngai (2004) destacam que a logística tem um papel essencial no aspecto de alavancar vantagem competitiva para as organizações. Desta forma, a busca por novas práticas de negócios e soluções podem vir a ajudar no sentido de que os objetivos sejam alcançados com sucesso (PERÇIN, 2009).

\section{OBJETIVOS E MÉTODO DE PESQUISA}

O objetivo geral do trabalho foi o de analisar o processo de transformação de uma transportadora tradicional em um operador logístico no sentido de agregar valor aos serviços prestados aos clientes e ampliar o seu nível de competitividade. Em acréscimo, foram estabelecidos os seguintes objetivos específicos: identificar as motivações que levaram a empresa em estudo a se transformar em um operador logístico, descrever as etapas de transformação do negócio, levantar as mudanças estratégias e operacionais decorrentes e analisar os resultados obtidos e que impactaram no desempenho e no nível de competitividade da empresa.

Quanto ao tipo de pesquisa, o trabalho pode ser caracterizado como uma pesquisa qualitativa de caráter exploratório (KING; HORROCKS, 2010; HENNINK; HUTTER; BAILEY, 2011), sendo implementada por meio de um estudo de caso único (YIN, 2009). Para a coleta de dados, foram realizadas entrevistas individuais em profundidade (FLICK, 2004; RIBEIRO; MILAN, 2004; KING; HORROCKS, 2010). As entrevistas foram conduzidas com uma abordagem semi-estruturada, mediante a 
aplicação de dois Roteiros Básicos de Questões (RIBEIRO; MILAN, 2004; KING; HORROCKS, 2010; HENNINK; HUTTER; BAILEY, 2011), aplicados em sessão única com os entrevistados. A duração média das entrevistas ficou em 1h 30min.

Para facilitar a posterior análise e interpretação dos dados, empregou-se a análise de conteúdo (WOLCOTT, 1994; BARDIN, 2004; SCHREIER, 2012). As entrevistas foram gravadas em meio eletrônico e transcritas (FLICK, 2004; RIBEIRO; MILAN, 2004; KING; HORROCKS, 2010), organizando-se os conteúdos a partir dos objetivos estabelecidos para a pesquisa.

Os roteiros foram aplicados a dois grupos de entrevistados. O primeiro deles foi utilizado para a coleta de dados com profissionais da Irapuru (Entrevistados A a D), enquanto que o segundo foi dirigido para os entrevistados pertencentes ao Grupo Randon (Entrevistados F a H). Isto ocorreu porque a Irapuru Transporte Ltda. pertenceu ao Grupo Randon entre os anos de 1960 à 1997, e por estas pessoas terem informações e vivências relevantes ao presente estudo de caso.

Quanto aos entrevistados, procurou-se identificar informantes-chave, os quais dominassem todo o processo de transformação da empresa e, sendo assim, foram definidos os critérios de seleção: cargo que ocupa / ocupou, tempo na empresa e liberdade de expressão em relação às questões propostas. Juntamente com a alta administração da empresa, foram identificados os profissionais (Figura 2):

Figura 2 - Perfil dos entrevistados

\begin{tabular}{|c|c|c|c|}
\hline Entrevistados & Cargo / Função dos Entrevistados & Realização & $\begin{array}{c}\text { Anos na } \\
\text { Empresa }\end{array}$ \\
\hline A & Diretor-Presidente e Proprietário da Empresa & $12 / 09 / 2011$ & 14 \\
\hline B & Gerente de Logística & $04 / 09 / 2011$ & 18 \\
\hline C & Gerente Administrativo & $04 / 09 / 2011$ & 8 \\
\hline D & Gerente Operacional & $12 / 09 / 2011$ & 15 \\
\hline E & Gerente Executivo (Jost, empresa do Grupo Randon) & $15 / 08 / 2011$ & 23 \\
\hline F & $\begin{array}{c}\text { Gerente de Suprimentos e Logística } \\
\text { (Master, Grupo Randon) }\end{array}$ & $09 / 08 / 2011$ & 19 \\
\hline G & Gerente de Atendimento (Master, Grupo Randon) & $09 / 08 / 2011$ & 40 \\
\hline H & Ex-Quotista da Cooperativa Randon & $02 / 08 / 2011$ & aposentado \\
\hline I & Diretor Corporativo & $11 / 08 / 2011$ & 41 \\
\hline
\end{tabular}

Também foi utilizada a observação direta, verificando-se in loco a estrutura e os processos da empresa, e a pesquisa documental, para a identificação e análise de informações provenientes da consulta de documentos disponíveis (BARDIN, 
2004; HENNINK; HUTTER; BAILEY, 2011). A identificação e análise de documentos servem para corroborar e valorizar as evidências obtidas por outras técnicas de pesquisa, no caso, das entrevistas individuais em profundidade (YIN, 2009). Desta forma, foram analisados os documentos disponibilizados pelos gestores da empresa, servindo para o aprofundamento das informações obtidas durante as entrevistas realizadas. Portanto, foram manuseados os seguintes documentos: Memorial Randon (1970-1997), Relatórios de Clientes (2003-2011), Relatórios de Faturamento (2003-2011) e Evolução dos Contratos (relacionamento com os clientes, 2003-2011).

\section{ESTUDO DE CASO}

\subsection{A Empresa em Estudo}

A Irapuru Transportes Ltda. foi fundada em 2 de janeiro de 1970, como uma das empresas do Grupo Randon, localizada na cidade de Caxias do Sul, no Estado do Rio Grande do Sul (RS). Porém, como o Grupo Randon resolveu se concentrar em seu negócio principal, produção e comercialização de implementos rodoviários, decidiu vendê-la, em 1997, à empresa Transporte Pellenz Ltda., que adotou a razão social Irapuru Transportes Ltda., por se tratar de uma marca conhecida no mercado.

A empresa é reconhecida por sua atuação como um operador logístico e conta com 1.433 funcionários, estando presente nos mercados do Mercosul e em, praticamente, todo o território brasileiro, atendendo cerca de 400 clientes, dentre eles, montadoras de veículos e indústrias de grande porte. Em 2011, o seu faturamento foi de $\mathrm{R} \$ 230,5$ milhões. Os serviços prestados são: gerenciamento de recebimento e almoxarifados, expedição, movimentação interna, desenvolvimento e implantação de serviços kanban, just in time, milk run, abastecimento de linhas, montagem e embalagem de kits, locação de equipamentos, terceirização de mão de obra, fluxo contínuo de informações, armazém, controle de estoque por meio de WMS (Warehouse Management System - Sistema de Gerenciamento de Armazém), além de TMS (Transport Management System - Sistema de Gerenciamento de Transporte), controle de programação de embarques, sistemas de comunicação EDI e o desenvolvimento de projetos para suprir as necessidades dos seus clientes. 
Preocupada em prestar um serviço de valor agregado aos clientes e aumentar a eficiência de suas operações, possui a certificação ISO 9001 (Organização Internacional de Normalização) e certificação SASSMAQ (Sistema de Avaliação de Segurança, Saúde, Meio-Ambiente e Qualidade), destacadas na sua política da qualidade, tendo o compromisso não só satisfazer as necessidades e as exigências de seus clientes, mas de antecipar-se a elas, atuando de forma pró-ativa na melhoria contínua dos serviços, buscando a retenção dos mesmos.

\subsection{Motivações para a Transformação do Negócio}

A empresa foi adquirida em 1997 e no processo de aquisição, os gestores não imaginavam, ainda, a transformação conceitual do negócio que estava por vir. Isso transcorreu, posteriormente, de forma natural, e não houve resistência nem interna e nem do mercado em relação à transformação da Irapuru, de uma transportadora tradicional para um operador logístico (ENTREVISTADO A). Para facilitar a compreensão a respeito deste processo, a Figura 3 apresenta as motivações que conduziram a empresa a se tornar um operador logístico:

Figura 3 - Motivações da transformação do negócio

(continua)

\begin{tabular}{|c|l|}
\hline Motivações & \multicolumn{1}{|c|}{ Evidências Empíricas } \\
\hline $\begin{array}{c}\text { Mudança } \\
\text { no foco } \\
\text { de atuação }\end{array}$ & $\begin{array}{l}\text { Foi preciso tomar uma decisão: [...] ou nos tornariamos um operador ou } \\
\text { ficaríamos como transportadora que iria posteriormente trabalhar para um } \\
\text { operador logístico. A empresa optou em se tornar um operador logístico e } \\
\text { entrou em diversos segmentos: pólo petroquímico, distribuição e } \\
\text { armazenagem [que antes não eram atendidos, aumentando a competitividade } \\
\text { da empresa] (ENTREVISTADO H). }\end{array}$ \\
\hline $\begin{array}{l}\text { Oportunidade } \\
\text { de mercado }\end{array}$ & $\begin{array}{l}\text { Esta decisão ocorreu em virtude do mercado: [...] o crescimento do mercado } \\
\text { abriu uma nova opção de serviço para as transportadoras e a carteira de } \\
\text { clientes que trabalhamos, que tem um nível de exigência muito alto, e também } \\
\text { a diversificação dos produtos destes clientes, sendo que a cada dia temos que } \\
\text { apresentar soluçães diferenciadas, tanto para transporte quanto para } \\
\text { armazenagem. Com isso, a transformação [conceitual e operacional do do } \\
\text { negócio] foi inevitável para que tivéssemos continuidade [possibilidade de } \\
\text { competir em uma perspectiva futura] na atividade e [viabilizar a consolidação } \\
\text { e] o crescimento da empresa (ENTREVISTADO B). }\end{array}$ \\
\hline
\end{tabular}


Figura 3 - Motivações da transformação do negócio

(conclusão)

\begin{tabular}{|c|c|}
\hline Motivações & Evidências Empíricas \\
\hline $\begin{array}{c}\text { Necessidades } \\
\text { dos clientes }\end{array}$ & $\begin{array}{l}\text { Evidenciou-se a preocupação dos principais gestores da empresa em } \\
\text { suprirem as expectativas dos clientes. Isto pode ser percebido pelo comentário } \\
\text { do Entrevistado A: [...] a Irapuru trabalhava com empresas multinacionais, cujo } \\
\text { foco era voltado para os seus negócios. [...] Nossos clientes já atuavam com } \\
\text { operadores logísticos e eles também queriam aqui ir [neste momento] para } \\
\text { está linha [tipo de atendimento]. } \\
\text { A empresa busca constantemente: [...] a satisfação do cliente, prestando } \\
\text { serviços com qualidade e com um preço justo (ENTREVISTADO C). }\end{array}$ \\
\hline $\begin{array}{l}\text { Diferencial } \\
\text { competitivo }\end{array}$ & $\begin{array}{l}\text { A empresa, a partir de sua transformação, começou a atuar em diversos } \\
\text { segmentos, tais como: pólo petroquímico, depósitos de distribuição e } \\
\text { armazenagem para terceiros, e a sua fórmula. [...] era sua flexibilidade em } \\
\text { trabalhar as particularidades dos clientes, adequando-se às suas } \\
\text { necessidades logísticas. Em contrapartida, a maioria dos concorrentes } \\
\text { adotava modelos prontos (até mesmo "concorrentes internacionais"), e isso } \\
\text { facilitou a aceitação da empresa no mercado (ENTREVISTADO H). } \\
\text { O Entrevistado A colocou que o diferencial da Irapuru no mercado é [...] ser } \\
\text { uma empresa que atende a qualquer tipo de problema, a qualquer hora, com } \\
\text { atendimento } 24 \text { horas por dia, bem estruturada desde a coleta até a entrega. } \\
\text { Sempre à disposição para atender possíveis eventualidades dos seus clientes. }\end{array}$ \\
\hline $\begin{array}{l}\text { Aumento } \\
\text { do volume } \\
\text { de negócios }\end{array}$ & $\begin{array}{l}\text { Em relação aos resultados financeiros, a partir da transformação do negócio, } \\
\text { mais especificamente em relação ao aumento do volume de negócios } \\
\text { (faturamento) da empresa, o Entrevistado } \mathrm{H} \text { mencionou que os negócios } \\
\text { [venda de serviços] começaram a acontecer um atrás do outro. Para vender o } \\
\text { serviço de transporte se vendia um pacote de serviços (serviços agregados). } \\
\text { O Entrevistado A destacou que: [...] de um mesmo negócio pôde se ter vários } \\
\text { serviços diferentes [o que estimulou a venda não mais de um serviço isolado, } \\
\text { por exemplo, apenas o de transporte, mas a venda de um pacote ou de um } \\
\text { conjunto de serviços, complementares, de valor agregado, o que impactou no } \\
\text { aumento do volume de negócios da empresa]. }\end{array}$ \\
\hline
\end{tabular}

\subsection{Etapas de Transformação do Negócio}

\section{A transformação do negócio passou por três etapas, cronologicamente} registradas, e com os seus principais processos, apresentadas na Figura 4:

Figura 4 - Etapas de transformação do negócio

\begin{tabular}{|c|l|l|}
\hline Etapas & Cronologia & Principais Processos Envolvidos em Cada uma das Etapas \\
\hline Conceitual & $1998-2000$ & $\begin{array}{l}\text { Entender o conceito e a aplicabilidade do termo "operador } \\
\text { logístico", dentro da empresa, o que, no Brasil, e na época, era algo } \\
\text { novo (inovador). }\end{array}$ \\
\hline Estruturação & $2001-2005$ & $\begin{array}{l}\text { Planejar, estruturar e iniciar a implementação das mudanças } \\
\text { (estratégicas e operacionais) necessárias para transformar a } \\
\text { empresa em um operador logístico. }\end{array}$ \\
\hline Consolidação & 2006 até.... & $\begin{array}{l}\text { Qualificar a estrutura da empresa, bem como os serviços ofertados } \\
\text { e prestados e consolidar a marca em seu mercado de atuação. }\end{array}$ \\
\hline
\end{tabular}


A empresa procurou estabelecer um alicerce sustentável, buscando conhecimento sobre o conceito e aplicabilidade do termo "operador logístico". Após a etapa de amadurecimento deste novo conhecimento, partiu para a estruturação da transição de transportadora para operador logístico, evidenciando-se na implementação de aspectos importantes: investimentos em ativos, profissionalização e mudança culturais. Atualmente, encontra-se na busca por consolidar a sua marca, trabalhando em conjunto com seus clientes na solução dos problemas e, de forma customizada, procurando se diferenciar dos concorrentes, incorporando valores relevantes para a construção de uma imagem favorável junto ao mercado.

\subsection{Mudanças Estratégicas e Operacionais Decorrentes}

O primeiro passo foi conhecer e incorporar o conceito de operador logístico, sua aplicabilidade e implicações. Para isso, em 1998, o proprietário da empresa se inscreveu na CICS - Câmara de Indústria, Comércio e Serviços, que mantinha um programa de cooperação técnica juntamente com o governo da Alemanha, com o intuito de auxiliar os empresários da região em adquirir novos conceitos, pelo qual havia a possibilidade de trazer executivos alemães aposentados com larga experiência em determinadas áreas, para o Brasil, a fim de prestarem consultoria às empresas da região. Por meio deste programa, as empresas interessadas, e que necessitavam deste tipo de profissional, pagariam somente as despesas destas pessoas com seu deslocamento (viagem ida e volta) e estadia.

Em decorrência do conhecimento oriundo da consultoria e visitas técnicas a empresas na Alemanha, constataram a necessidade de adequar alguns aspectos culturais e estruturais para dar sustentação ao novo modelo de negócios que, no Brasil, era muito recente. A partir disso, houve a necessidade de algumas mudanças estratégicas e operacionais. Aliás, o Entrevistado B ressalta que foi necessária uma:

[...] mudança cultural da empresa de transporte simples, pequena, para uma empresa de ponta em termos de transporte e, depois, de logística. E esta mudança de cultura é fundamental. Estávamos acostumados a um ritmo de trabalho e mudou totalmente, inclusive, o envolvimento das pessoas e a sua dedicação [compromisso]. Hoje, temos que trabalhar 24 horas por dia e isso exige uma mudança de cultura e de postura. Viemos agregando valor, 
atendendo bem o cliente, nos ajudando [mutuamente]. O nosso "produto" [entendido como um resultado final] é um serviço [de qualidade] e se as pessoas se ajudarem é muito importante para a operação.

No caso da empresa, o seu processo de transformação em um operador logístico implicou na incidência de mudanças estratégicas e operacionais. Sendo assim, são apresentadas, na Figura 5, as principais mudanças ocorridas.

Figura 5 - Mudanças estratégicas e operacionais

\begin{tabular}{|c|c|c|}
\hline Etapas & Mudanças Estratégicas & Mudanças Operacionais \\
\hline Conceitual & \begin{tabular}{llrr} 
Incorporação & do & \multicolumn{2}{r}{ conhecimento } \\
necessário sobre o & conceito de \\
operador & logístico & e & suas \\
implicações. & & & \\
\end{tabular} & $\begin{array}{l}\text { Alteração de certas funções e do } \\
\text { comportamento dos profissionais em } \\
\text { relação ao novo conceito. }\end{array}$ \\
\hline Estruturação & $\begin{array}{l}\text { Adequação da organização ao novo } \\
\text { conceito. } \\
\text { Alteração do organograma da } \\
\text { empresa (adaptação das equipes de } \\
\text { trabalho e funções desempenhadas). }\end{array}$ & $\begin{array}{l}\text { Aumento (volume) e qualificação de ativos } \\
\text { tais como: frota de veículos, implementos e } \\
\text { CDs (área física). } \\
\text { Incremento nos investimento em novas } \\
\text { tecnologias (EDI, WMS e TMS). } \\
\text { Capacitação dos profissionais. } \\
\text { Implantação de ferramentas da qualidade. } \\
\text { Estruturação dos processos de gestão e da } \\
\text { parte operacional (área comercial, } \\
\text { atendimento aos clientes e serviços). }\end{array}$ \\
\hline Consolidação & $\begin{array}{l}\text { Qualificação permanente dos } \\
\text { serviços. } \\
\text { Foco na retenção e, se possível, } \\
\text { lealdade dos clientes. } \\
\text { Aprofundamento das parcerias de } \\
\text { longo prazo (estreitamento dos } \\
\text { relacionamentos com os clientes). }\end{array}$ & $\begin{array}{l}\text { Capacitação contínua para o atendimento } \\
\text { aos clientes e qualidade das operações. } \\
\text { Manutenção de padrões nas operações. } \\
\text { Adequação dos seus serviços às } \\
\text { necessidades dos clientes. }\end{array}$ \\
\hline
\end{tabular}

\subsection{Resultados Obtidos}

A transformação do negócio possibilitou que a empresa passasse a ser vista no mercado...

[...] de uma forma diferente. No sentido de negócios, abriu várias portas [novas oportunidades de negócio] (ENTREVISTADO A).

De acordo com o Entrevistado C, a empresa procurou...

[...] desenvolver contratos nos quais foram melhorados alguns processos. Foi possível oferecer mais serviços para o mesmo cliente, desenvolvendo vários projetos customizados para atender a necessidades específicas dos clientes. 
Tendo em vista o desenvolvimento de projetos customizados, passou a existir a necessidade de definir alguns aspectos caso a caso em relação às operações:

[...] definições sobre: área física, pessoas, equipamentos e detalhamento de todo o escopo [do projeto] para depois implementá-lo. É muito importante é o planejamento, se caso não for bem planejado a chance de dar problema é grande (ENTREVISTADO B).

No que tange à possibilidade de retenção, ou mesmo de fidelização de clientes, o Entrevistado D argumenta que a empresa ficou...

[...] mais próxima dos seus clientes, trabalhando em parceria, buscando resolver [as demandas existentes] e construir o melhor resultado na cadeia logística. Outro ponto é estarmos presentes no dia a dia [do cliente]. Isso permite sugerir melhorias e alavancar novos negócios, ou seja, termos que buscar acompanhar as necessidades do cliente na mesma velocidade [em que surgem suas necessidades].

$E$ isso trouxe uma maior satisfação do cliente. A empresa entendeu que deveria se adequar...

[...] ao perfil do cliente, sem impor condições inflexíveis, muitas restrições, ou seja, trabalhamos 24 horas por dia e 7 dias da semana para o cliente que necessitar os nossos serviços (ENTREVISTADO C).

Este tipo de compromisso da empresa, faz com que o cliente:

[...] esteja mais envolvido contigo. Permite também que a troca de um operador logístico não seja tão fácil como uma transportadora tradicional. Uma transportadora [com problemas de qualidade nos serviços, o cliente] troca na hora, um operador logístico não. É uma vantagem do operador, pois a relação é mais complexa. $E$ isto se dá em função do nível de serviço ofertado, como, por exemplo: coleta programada (o que reduz o estoque do cliente), follow-up, armazenagem e atendimento no sistema kanban (ENTREVISTADO A).

Toda essa mudança na forma de atuar da empresa também possibilitou a atração de novos clientes e/ou o desenvolvimento de novos negócios. Inclusive, o Entrevistado $G$ afirmou que, principalmente em função da elevação no nível de qualidade dos serviços da empresa, a atração de novos clientes foi muito rápida. Sob a ótica dos números, a Tabela 1 apresenta a evolução do número de contratos (clientes atendidos regularmente) e do número de clientes ativos da empresa em relação ao período de transição da transformação do negócio. 
Tabela 1 - Evolução do número de contratos e do número de clientes ativos

$\begin{array}{ccccc}\begin{array}{c}\text { Período } \\ \text { (Anos) }\end{array} & \begin{array}{c}\text { Número } \\ \text { de Clientes }\end{array} & \begin{array}{c}\text { Variação } \\ \text { (em \%) }\end{array} & \begin{array}{c}\text { Número de } \\ \text { Contratos }\end{array} & \begin{array}{c}\text { Variação } \\ \text { (em \%) }\end{array} \\ 1997 \text { a 2002 } & 40 & - & 11 & - \\ 2003 \text { a } 2011 & 400 & 900 & 24 & 118,18\end{array}$

Fonte: Relatórios de Contratos e de Clientes (1997-2010).

A média de duração dos contratos da empresa com seus parceiros de negócio (clientes) é de 7 anos e 4 meses. O aumento do número de contratos e de clientes ativos e, consequentemente, do volume de negócios (faturamento) da empresa, repercutiu positivamente nos resultados financeiros (ENTREVISTADO A). Quando a Irapuru foi adquirida, em 1997, apresentava um faturamento médio anual de $R \$ 860$ mil, o qual chegou, em 2000, a R\$1,5 milhões. O seu crescimento ocorreu na época da transformação do negócio. No período entre 2003 e 2004, houve mais um aumento em seu faturamento na ordem de $75 \%$.

Entre os anos de 2008 e 2009, porém, houve um declínio no volume de negócios da empresa em função da crise mundial, principalmente pela bolha imobiliária nos Estados Unidos, que ocasionou a falência de muitos gigantes da economia mundial. Em 2011, a empresa apresentou um faturamento de $\mathrm{R} \$ 223,5$ milhões. Para facilitar a compreensão da evolução do faturamento da empresa, segue a Tabela 2:

Tabela 2 - Evolução do faturamento da empresa

\begin{tabular}{lcc} 
Anos & Faturamento Anual (em R\$) & Variação (em \%) \\
2003 & $54.000 .000,00$ & - \\
2004 & $95.000 .000,00$ & 75,93 \\
2005 & $118.000 .000,00$ & 24,21 \\
2006 & $142.000 .000,00$ & 20,34 \\
2007 & $186.000 .000,00$ & 30,99 \\
2008 & $215.000 .000,00$ & 16,28 \\
2009 & $180.000 .000,00$ & $-19,28$ \\
2010 & $223.000 .000,00$ & 23,88 \\
2011 & $223.500 .000,00$ & 0,22 \\
\hline
\end{tabular}

Fonte: Relatórios de Faturamento (2003-2011).

\section{CONSIDERAÇÕES FINAIS}

Conforme comentado, as empresas estão, em boa parte, terceirizando suas funções logísticas e se focando mais em seus negócios, e isso vem propiciando muitas oportunidades de negócio para os operadores logísticos (CHRISTOPHER; 
TOWILL, 2001). Por meio de serviços de qualidade garantida, as empresas procuram se diferenciar (MILAN, 2006), o que possibilita a elas estabelecer, manter e aprofundar relacionamentos duradouros com seus clientes, estimular a retenção dos mesmos e aumentar o seu volume de negócios.

Em função das mudanças do mercado e a percepção dos gestores da Irapuru, os mesmos vislumbraram as novas necessidades dos clientes e buscaram se transformar de uma transportadora tradicional em um operador logístico para atender as diferentes demandas de seus clientes e, com isso, diferenciar-se dos seus concorrentes, tornando-se uma empresa mais competitiva. Inclusive, Langley et al. (2005) reforçam que os operadores logísticos, por meio da incorporação de novas atividades, exigidas pelos clientes, estão mudando a sua forma de atuação no mercado ao longo dos anos, demonstrando uma maior maturidade.

Esta mudança transcorreu de forma natural, evolutiva, sendo que a empresa primeiramente procurou conhecer o conceito do que seria, de fato, um operador logístico, já que no Brasil era muito recente, o que se deu por meio de um consultor alemão. Somente após tal entendimento, os gestores partiram para a etapa de estruturação da empresa, havendo a necessidade de realizar mudanças tanto estratégicas quanto operacionais para se adequar à nova forma de atuação no mercado e como iria prestar os serviços aos seus clientes. $E$ isto pode servir para empresas que venham a passar por um processo semelhante, pois exige mudanças culturais na empresa e aspectos mais pontuais, como, por exemplo: readequação do organograma da empresa, e funções dos profissionais envolvidos, capacitação e aperfeiçoamento de pessoal, investimento em estrutura (área física, frota de veículos e implementos) e em recursos de TI e implantação de ferramentas da qualidade.

Durante o seu processo de aprendizado, a empresa apresentou dificuldades operacionais em função do aumento no número de funcionários, em termos de qualificação dos profissionais, e na demanda pelos serviços, por parte dos clientes, o quê, de certa forma, também serviu como experiência e aprendizado da empresa em relação à coordenação das atividades e ao gerenciamento do novo conceito (a transformação da empresa em um operador logístico), para, posteriormente, evoluir na estruturação da empresa e agregar novos segmentos de atuação no mercado, como foi o caso dos segmentos petroquímico, siderúrgico e das montadoras. 
Por isso, para que as empresas ampliem o seu nível de competitividade é imprescindível o desenvolvimento das relações formais (da empresa em relação aos seus funcionários e da empresa em relação aos seus clientes e fornecedores), no longo prazo (MURPHY; POIST, 2000; MILAN; DORION; MATOS, 2012), sendo que a colaboração é um elemento essencial à integração entre as partes envolvidas, facilitando a comunicação inter-funcional (FLYNN; HUO; ZHAO, 2010). Neste contexto, Alfredsson e Hertz (2003) destacam que a confiança e a comunicação entre as partes é vital.

Outro aspecto identificado no caso estudado, é que os relacionamentos somente serão fortalecidos se os clientes perceberem a existência de vantagens (no caso, um atendimento diferenciado e serviços de qualidade superior, em comparação a fornecedores alternativos) (LANGLEY et al., 2005). Neste aspecto, a diferenciação de custos, repercutindo em um preço justo, a segmentação de mercado, com foco e um posicionamento competitivo claro, e os serviços, de qualidade superior, são as principais formas de melhorar o desempenho e o lucro de um operador logístico (PANAYIDES, 2004; SUM; TEO, 1999).

As empresas geralmente procuram consolidar o negócio em uma perspectiva de longo prazo, agregando valor aos clientes por meio de serviços diferenciados. $E$ isso ficou evidenciado no decorrer da pesquisa, o que é demonstrado pela flexibilidade da empresa em trabalhar com as particularidades de cada um dos seus clientes, apresentando soluções customizadas que agregam valor aos serviços prestados, gerando a satisfação de seus clientes. Além de satisfazer os clientes, isso ainda possibilita a abertura de novas oportunidades de negócio.

\section{REFERÊNCIAS}

AKTAS, E.; ULENGIN, F. Outsourcing logistics activities in Turkey. The Journal of Enterprise Information Management, v.18, n.3, p.316-329, 2005.

ALFREDSSON, M.; HERTZ, S. Strategic development of third party logistics providers. Industrial Marketing Management, v.32, n.2, p.139-149, 2003.

BARAD, M.; SAPIR, D.E. Flexibility in logistics systems - modeling and performance evaluation. International Journal of Production Economics, v.85, n.2, p.155-170, 2003. 
BARDI, E.J.; TRACEY, M. Transportation outsourcing: a survey of US practices. International Journal of Physical Distribution and Logistics Management, v.3, n.5, p.15-21, 1991.

BARDIN, L. Análise de conteúdo. Lisboa: Edições 70, 2004.

BASK, A.H. Relationships among TPL providers and members of supply chains: a strategic perspective. Journal of Business \& Industrial Marketing, v.16, n.6, p.470-486, 2001.

BENTZ, B.A.; LIEB, R.C. The use of third-party logistics services by large American manufactures: the 2004 survey. Transportation Journal, v.44, n.2, p.5-15, 2005.

BERGLUND, M.P.; SHARMAN, G.; WANDEL, S. Third-party logistics: is there a future? International Journal of Logistics Management, v.10, n.1, p.59-70, 1999.

BHATNAGAR, R.; VISWANATHAN, S. Re-engineering global supply chains: alliances between manufacturing and global logistics service providers. International Journal of Physical Distribution \& Logistics Management, v.30, n.1, p.13-34, 2000.

BOT, B.L.; NEUMANN, C.S. Growing pains for logistics outsourcers. The McKinsey Quarterly, v.15, n.2, p.68-77, 2003.

BOURLAKIS, C.; BOURLAKIS, M. Information technology safeguard, logistics asset specificity and 4th party logistics network creation in the food retail chain. Journal of Business e Industrial Marketing, v.20, n.2-3, p.88-98, 2005.

BOWERSOX, D.J.; CLOSS, D.J.; STANK, T.P. How to master cross-enterprise collaboration. Supply Chain Management Review, v.7, n.4, p.18-29, 2003.

CHEONG, M.F.F. Logistics outsourcing and 3PL challenges. Logistics and Transportation Review, v.29, n.4, p.363-370, 2004.

CHRISTOPHER, M.; TOWILL, D. An integrated model for the design for agile supply chains. International Journal of Physical Distribution \& Logistics Management, v.31, n.4, p.235-246, 2001.

COYLE, J.J.; BARDI, E.J.; LANGLEY, J. The management of business logistics. $7^{\text {th }}$ edition. New York: Cengage Learning, 2003.

DAUGHERTY, P.J.; STANK, T.P.; ROGERS, D.S. Third party logistics service providers: purchasers perceptions. International Journal of Purchasing and Materials Management, v.32, n.2, p.23-29, 1996.

DORNIER, P.P.; ERNEST, R.; FENDER, M.; KOUVELIS, P. Global operations and logistics. $1^{\text {st }}$ edition. New York: John \& Wiley Sons, 1998. 
EVANGELISTA, P.; SWEENEY, E. Technology usage in the supply chain: the case of small 3PLs. The International Journal of Logistics Management, v.17, n.1, p.55-74, 2003.

FERNANDES, S.T; MARINS, F.A.S. Aplicação do lean six sigma na logística de transporte. Produção Online, v.12, n.2, p.297-327, 2012.

FLEURY, P.F. Vantagens competitivas e estratégicas no uso de operadores logísticos. In: FLEURY, P.F.; WANKE, P.; FIGUEREDO, K. (org.). Logística empresarial. São Paulo: Atlas, 2004. cap.4, p.125-152.

FLICK, U. Uma introdução à pesquisa qualitativa. 2. ed. Porto Alegre: Bookman, 2004.

FLINT, D.J.; LARSSON, E.; GAMMELGAARD, B. Logistics innovation: a customer value oriented social process. Journal of Business Logistics, v.26, n.1, p.113-147, 2005.

FLYNN, B.B.; HUO, B.; ZHAO, X. The impact of supply chain integration on performance: a contingency and configuration approach. Journal of Operations Management, v.28, n.1, p.58-71, 2010.

FUCHS, H.J. Fareast goes west: new opportunities for Asian brands in Europe. Asia Pacific Journal of Marketing and Logistics, v.15, n.3, p.20-33, 2003.

GRACHT, H.A.; DARKOW, I.L. Scenarios for the logistics services industry: Delphibased analysis for 2025. International Journal of Production Economics, v.27, n.1, p.46-59, 2010.

GUNASEKARAN, A.; NGAI, E.W.T. 3PL: experiences from China resources logistics. International Journal of Logistics Systems an Management, v.1, n.1, p.81-97, 2004.

HAMEL, G.; PRAHALAD, C.K. Competindo pelo futuro. Rio de Janeiro: Campus, 2000.

HEIDE, J.B.; JOHN, G. The role of dependence balancing in safeguarding transaction-specific assets in conventional channels. Journal of Marketing, v.52, n.12, p.20-35, 1988.

HENNINK, M.; HUTTER, I.; BAILEY, A. Qualitative research methods. London: Sage, 2011.

JESPERSEN, B.D.; SKJOETT-LARSEN, T. Supply chain management: in theory and practice. Copenhagen: Copenhagen Business School Press, 2005. 
JOHNSON, E.; PYKE, D. Supply chain management. Production and Operations Management Society, 2000.

JUNQUEIRA, E.R.; CORRAR, L.J.; MORAES, R.O.; OYADOMARI, J.C.T. Modelo Novaes para análise da produtividade e da eficiência dos operadores logísticos do Brasil: um estudo de sua aplicabilidade para os anos de 2005 e 2006 . Produção Online, Edição Especial, p. 1-18, 2007.

KING, N.; HORROCKS, C. Interviews in qualitative research. London: Sage, 2010. LAISI, M.; HILMOLA, O.P.; SUTELA, M. North European companies' relation with Russia and China: future outlook on transport flows. Benchmarking: An International Journal, v.19, n.1, p.11-29, 2012.

LANGLEY, C.J.J.; VAN, D.E.; ANG, A.; SYKES, S.R. Third-party logistics - results and findings of the $10^{\text {th }}$ annual study. Atlanta: Georgia Institute of Technology, 2005.

LARGE, R.O. The influence of Customer-specific adaptations on the performance of third-party-logistics relationship-document studies and propositions. International Journal of Logistics Research and Applications, v.10, n.2, p.123-133, 2007.

LIEB, R.C.; MILLER, R.A. The use of third-party logistics services by large US manufactures, the 2000 survey. International Journal of Logistics: Research and Applications, v.5, n.1, p.1-12, 2002.

LIEB, R.C.; RANDALL, H.L. A comparison of the use of third-party logistics services by large American manufactures 1991, 1994 and 1995. Journal of Business Logistics, v.17, n.1, p.305-320, 1996.

LIU, H.T.; WANG, W.K. An integrated fuzzy approach for provider evaluation and selection in third party logistics. Expert Systems with Application, v.36, n.3, p.4.387-4.398, 2009.

LYNCH, C.F. Logistics outsourcing. Oak Brook: Council of Logistics Management, 2000.

MANUJ I.; MENTZER J.T. Global supply chain risk management. Journal of Business Logistics, v.29, n.1, p.133-155, 2008.

McGINNIS, M.A.; KOHN, J.W. Logistic strategy revisited. Journal of Business Logistics, v.23, n.3, p.1-17, 2002.

MENEZES, T.M.; GUIMARÃES, M.G.; SELLITTO, M.A. Medição de indicadores logísticos em duas operações de montagem abastecidas por cadeias de suprimentos. Produção Online, v.8, n.1, p.1-23, 2008. 
MILAN, G.S. Diferenciação por serviços e posicionamento competitivo. In: VIEIRA, G.B.B. (org.). Logística e distribuição física internacional. São Paulo: Lex, 2006. cap.3, p.71-96.

MILAN, G.S.; DORION, E.; MATOS, J.A.R. Distribution channel conflict management: a Brazilian experience. Benchmarking: An International Journal, v.19, n.1, p.32-51, 2012.

MIN, H.; JOO, S.J. Benchmarking third-party logistics provider using data envelopment analysis: an update. Benchmarking: An International Journal, v.16, n.5, p.572-587, 2009.

MOURA, D.A.; BOTTER, R.C. O transporte por cabotagem no Brasil potencialidade para a intermodalidade visando a melhoria do fluxo logístico. Produção Online, v.11, n.2, p.592-617, 2011.

MURPHY, P.R.; POIST, R.F. Third-party logistics: some user versus provider perspectives. Journal of Business Logistics, v.21, n.1, p.121-133, 2000.

NEUSCHEL, R.P.; RUSSELL, D.M. Customer driven marketing in the transportation logistics industry. International Journal of Logistics Management, v.9, n.9, p.99106, 1998.

PALMATIER, R.W.; DANT, R.P.; GREWAL, D. A comparative longitudinal analysis of theoretical perspectives of interorganizational relationship performance. Journal of Marketing, v.71, n.41, p.172-194, 2007.

PANAYIDES, P.M. Logistics service providers: an empirical study of marketing strategies and company performance. International Journal of Logistics:

Research and Applications, v.7, n.1, p.1-15, 2004.

PERÇIN, S. Evaluation of third-party (3PL) providers by using a two-phase AHP and TOPSIS methodology. Benchmarking: an International Journal, v.16, n.5, p.588604, 2009.

PICININ, C.T.; KOVALESKI, J.L.; REIS, D.R. Aplicação de transferência de tecnologia em prática de gerenciamento de risco logístico. Produção Online, v.10, n.1, p.124-141, 2012.

RAO, K.; YOUNG, R.R. Global supply chains: factors influencing outsourcing of logistics functions. International Journal of Physical Distribution \& Logistics Management, v.24, n.6, p.11-19, 1994.

RAO, P.S.; SWARUP, S. Business intelligence and logistics. Florida: Wipro Technologies, 2001. 
RAZZAQUE, M.A.; SHENG, C.C. Logistics outsourcing: literature review. International Journal of Physical Distribution \& Logistics Management, v.28, n.2, p.89-107, 1998.

RIBEIRO, J.L.D.; MILAN, G.S. Planejando e conduzindo entrevistas individuais. In: RIBEIRO, J.L.D.; MILAN, G.S. (Eds.). Entrevistas individuais. Porto Alegre: FEEng/UFRGS, 2004. cap.1, p.9-22.

SANTOS, R.F.; SOUZA JUNIOR, E.C.; BOUZADA, M.A.C. A aplicação da programação inteira na solução logística do transporte de carga: o solver e suas limitações na busca pela solução ótima. Produção Online, v.12, n.1, p.185-204, 2012.

SCHREIER, M. Qualitative content analysis in practice. London: Sage Publications, 2012.

SEMEIJN, J. Service priorities in international logistics. International Journal of Logistics Management, v.6, n.1, p.27-36, 1995.

SIMCHI-LEVI, D.; SNYDER, L.; WATSON, M. Strategies for uncertain times. Supply Chain Management Review, v.41, n.1, p.11-12, 2002.

SINK, H.L.; LANGLEY, J.C. A managerial framework for the acquisition of third party logistics services. Journal of Business Logistics, v.18, n.2, p.163-189, 1997.

SINK, H.L.; LANGLEY, J.C.; GIBSON, B.J. Buyer observations of the US third-party logistics market. International Journal of Physical Distribution \& Logistics Management, v.26, n.3, p.38-46, 1996.

SKJOETT-LARSEN, T. Third party logistics: from an interorganizational point of view. The International Journal of Physical Distribution \& Logistics Management, v.30, n.2, p.112-127, 2000.

SO, S.; KIM, J.; CHEONG, K.; CHO, G. Evaluating the service quality of third-party logistics service providers using the analytic hierarchy process. Journal of Information Systems and Technology Management, v.3, n.3, p.261-270, 2006.

SOUZA, D.V.S.; KLIEMANN NETO, F.J.; ANZANELLO, M. J. Avaliação de desempenho da cadeia de suprimentos balizada por critérios de competitividade empresarial. Produção Online, v.12, n.3, p.756-778, 2012.

STANK, T.P.; GOLDSBY, T.F. A framework for transportation decision making in an integrated supply chain. Supply Chain Management: an International Journal, v.5, n.2, p.71-77, 2000. 
STOCK, G.; GREIS, N.; KASARDA, J. Logistics, strategy and structure: a conceptual framework. International Journal of Operations and Production Management, v.18, n.1, p.37-52, 1998.

STOCK, J.R.; LAMBERT, D.M. Strategic logistics management. $4^{\text {th }}$ edition. New York: McGraw-Hill, 2001.

SUM, C.C.; TEO, C.B. Strategic posture of logistics service providers in Singapore. International Journal of Physical \& Logistics Management, v.29, n.9, p.588-605, 1999.

SVENSSON, G. The impact of outsourcing on inbound flows. International Journal of Logistics Management, v.12, n.1, p.21-35, 2001.

TIBBEN-LEMBKE, R.S.; ROGERS, D.S. Real options: applications to logistics and transportation. International Journal of Physical Distribution \& Logistics Management, v.36, n.4, p.252-270, 2006.

TUCEN, G.; ALPAN, G. Risk assessment and management for supply chain networks: a case study. Computers in Industry, v.61, n.3, p.250-259, 2010.

VAN DAMME, D.A.; PLOSS VAN AMSTEL, M.J. Outsourcing logistics management activities. International Journal of Logistics Management, v.7, n.2, p.85-95, 1996.

VAN HOEK, R.I.; CHONG, I. Epilogue UPS Logistics: practical approaches to the esupply chain. International Journal of Physical Distribution \& Logistics Management, v.31, n.6, p.463-468, 2001.

VAN LAARHOVEN, P.; BERGLUNG, M.; PETER, M. Third-party logistics in Europe: five years later. International Journal of Physical Distribution \& Logistics Management, v.30, n.5, p.425-442, 2000.

VASILIAUSKAS, A.V.; BARYSIENE, J. Review of current state of European 3PL market and its main challenges. Computer Modeling and New Technologies, v.12, n.2, p.17-21, 2008.

VIEIRA, G.B.B.; MILAN, G.S.; OTT, M.C. Avaliação da qualidade dos serviços de um prestador de serviços logísticos (PSL) e seus desdobramentos. In: VIEIRA, G.B.B.; SANTOS, C.H.S. (org.). Logística e gestão portuária. Caxias do Sul: EDUCS, 2008. cap.1, p.15-32.

VIRUM, $\mathrm{H}$. Third party logistics development in Europe. Logistics and Transportation Review, v.29, n.4, p.355-361, 1993.

WAGNER S.M.; BODE, C. An empirical examination of supply chain performance along several dimensions of Risk. Journal of Business Logistics, v.29, n.1, p.307325, 2008. 
WOLCOTT, H.F. Transforming qualitative data. Thousand Oaks: Sage, 1994.

WONG, Y.Y.; MAHER, T.E.; NICHOLSON, J.D.; GURNEY, N.P. Strategic alliances in logistics outsourcing. Asia Pacific Journal of Marketing and Logistics, v.12, n.4, p.3-21, 2000.

YIN, R.K. Case study research. $4^{\text {th }}$ edition. New York: Sage, 2009.

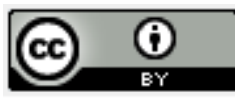

Artigo recebido em 05/09/2012 e aceito para publicação em 19/04/2013. 